\title{
CÓMO HA GAMBIADO EL GONVENTO. DESDE LA HERMANA SAN SULPICIO HASTA TERESA, EL CUERPO DE CRISTO, PASANDO POR OTROS GONVENTOS DEL GINE ESPAÑOL
}

\author{
María Jesús Ruiz Muñoz \\ Universidad de Málaga
}

El estudio de los medios audiovisuales resulta de gran utilidad para obtener detalles acerca de la vida cotidiana, los valores, los gustos, las ilusiones y los mitos que sirven para definir un colectivo en una época y en un lugar concreto. Además, por sus características intrínsecas, el medio cinematográfico es particularmente efectivo en la transmisión de normas sociales y dogmas ideológicos, pero también puede convertirse en un instrumento privilegiado a la hora de cuestionar los principios vigentes en su entorno e incluso contribuir a transformarlos. En las películas se reflejan los modos de vida, los hábitos y las formas de pensamiento de una sociedad, desde una doble lectura: por una parte, queda implícito el imaginario social del espacio y tiempo en que se realiza la película y, en caso de que sea otro el ambiente en el que transcurre el relato, subyace un nuevo entorno cuya representación estará condicionada en mayor o menor medida por el contexto en el que se ha creado la obra.

También debe considerarse, por supuesto, la influencia de aspectos inherentes a la subjetividad de los artífices de la obra, como sus creencias, su ideología y las características de su entorno político, social y cultural. Asimismo, a través del lenguaje específico del medio cinematográfico, en el que se combina una serie de códigos narrativos que varían según la época de que se trate, se generan connotaciones emocionales para conectar con los espectadores y se expresa el clima existente en una determinada sociedad.

A grandes rasgos, podemos afirmar que la construcción narrativa del relato fílmico se sustenta fundamentalmente en tres pilares: el personaje, la acción y el conflicto, de cuya interacción resulta la estructura dramática. La caracterización del personaje está determinada por su dimensión física, psicológica y sociológica, mientras que la evolución del personaje dependerá de sus motivaciones, acciones, objetivos y conflictos (Galán, 2007). En definitiva, un personaje constituye "el alma de una historia", es "el que genera afectos y aversiones, identi- 
ficación o distancia, simpatía o abierta antipatía, es el que más allá de la historia y los efectos visuales puede tocar el corazón de cada uno de los espectadores" (Rivera, 2008:19). Por ello, además, los personajes resultan especialmente eficaces como transmisores de modelos de socialización. Así pues, el análisis de personajes resulta adecuado a la hora de profundizar en el imaginario social existente dentro de un contexto de producción determinado.

Contemplando las premisas descritas, abordamos en el presente trabajo el estudio de la representación de la figura religiosa femenina en las películas de ficción del cine español.

\section{VÍRGENES, SANTAS Y ALEGRES NOVICIAS CASADERAS}

En los años veinte, el cine español encontró en los argumentos de clásicos del teatro y la zarzuela un patrón más que apropiado para atraer la atención de las clases populares. Al final del período mudo, Florián Rey obtuvo sus primeros éxitos con La hermana San Sulpicio (1927), una adaptación de la obra homónima de Armando Palacio Valdés, y Los claveles de la Virgen (1929), que marcaron el comienzo de su fructífero tándem con Imperio Argentina. En 1934, el director realiza una nueva versión de La hermana San Sulpicio, con su actriz predilecta y Miguel Ligero encabezando el reparto. Se trata de una comedia que relata la historia de Gloria Alvargonzález, una rica y bella heredera, que ingresa vocacionalmente en un convento y se enamora de Ceferino Sanjurjo, un médico gallego con el que finalmente se casará después de colgar los hábitos.

Desde luego, las convenciones que rigen esta película no resultan demasiado acordes con el espíritu modernizador del régimen republicano. En este sentido, es necesario recordar que, ya entonces, las principales productoras estaban en manos de una burguesía conservadora que, con el paso del tiempo, simpatizaría con la dictadura franquista. En lo que respecta a la caracterización de Gloria, puesto que es una religiosa, llama la atención su temperamento dicharachero y su inclinación por el cante y el baile. Debemos tener presente que, en este periodo, se constató la rentabilidad de la utilización de fórmulas narrativas en las que "la música sirve para dinamizar la acción y para fidelizar a un espectador que ya estaba habituado a otros espectáculos musicales" (Sánchez et al, 2009:337). En la década de los treinta, también empezó a configurarse un star system nacional, en el que las actrices folclóricas andaluzas, convertidas en auténticos símbolos, desempeñaron un papel esencial (Ruiz y Sánchez: 2008: 32-33). En 1952, se realizó otra versión de la exitosa Hermana San Sulpicio (Luis Lucia), protagonizada por Carmen Sevilla y Jorge Mistral.

La etapa franquista, en la que el régimen y la Iglesia católica comulgaron en cuestiones políticas, morales y espirituales, estuvo profundamente marcada por la instrumentalización ideológica del cine. Para tal fin, se hizo hincapié en el componente costumbrista de las películas, continuando el fortalecimiento de la línea del género folclórico, representada por aquellos mitos femeninos estereotipados con los que el público podía sentirse identificado y soñar despierto. Asimismo, se llevó a cabo una considerable producción de cine de temas religiosos que contribuyesen al adoctrinamiento de una sociedad marcada por las duras circunstancias de la posguerra española. Estas obras giraban en torno al enaltecimiento de figuras de santos, sacerdotes y monjas de vidas ejemplares, dichosos por su inmensa fe y admirables por sus sacrificios para entregarse a ayudar a los marginados y los más débiles. En la mayor parte de los casos, los recursos narrativos del melodrama se pusieron eficazmente al servicio de estas historias para reforzar su potente carga emotiva y canalizar así, de manera 
más depurada, los valores que el régimen pretendía transmitir. Entre las hagiografías protagonizadas por mujeres, cabe destacar títulos como Reina Santa (Rafael Gil, 1949), acerca de Santa Isabel de Aragón, reina de Portugal, Sor Angélica (Joaquín L. Romero Marchent, 1954) y Teresa de Jesús (Juan de Orduña, 1962). También resultan significativas las reconstrucciones de milagros, en las que los personajes principales son niñas, como La señora de Fátima (Rafael Gil, 1951) y Aquella joven de blanco (León Klimovski, 1965), basada en la biografía de Bernardette de Lourdes. A caballo entre lo folclórico y lo religioso, encontramos excepciones como la comedia La Hermana Alegría (Luis Lucia, 1954), en la que Lola Flores encarna a una monja graciosa y bondadosa, que emplea unas técnicas pedagógicas muy atípicas.

En general, en esta clase de películas, las religiosas suelen presentar perfiles psicológicos más débiles que los personajes masculinos análogos y, además, afrontan sus conflictos de un modo pasivo. Los problemas terrenales de estas vírgenes, santas y modélicas religiosas se resuelven con más frecuencia gracias a la intervención divina, mientras que a los sacerdotes se les atribuyen mayores habilidades para desenvolverse en los asuntos mundanos y sus labores en el seno de la comunidad son más complejas. Sirvan como ejemplo para la comparación La mies es mucha (José Luis Sáenz de Heredia, 1949) y Balarrasa (José Antonio Nieves Conde, 1950), ambas protagonizadas por Fernando Fernán Gómez, en las que se ensalza llamativamente la figura del misionero.

\section{MODERNAS, PERO COMO MANDAN LOS CÁNONES}

La década de los sesenta y el comienzo de los setenta en España estuvieron marcados por el incipiente desarrollo del país. El progreso económico, el crecimiento de las ciudades y la apertura de fronteras desencadenaron importantes cambios en la forma de vida, en el modelo familiar y en los modos de relación de los ciudadanos. La aceleración sin parangón de la movilidad social determinó una nueva configuración de la estructura de la población, debido al surgimiento de una amplia clase media que tenía acceso a la propiedad privada y a los novedosos bienes de consumo, que ha sido popularmente denominada la burguesía del seiscientos. Por su parte, la Iglesia católica española se vio relativamente influenciada por el espíritu renovador del Concilio Vaticano II.

El cine se hizo eco en gran medida de estas transformaciones, haciendo especial hincapié en el contraste entre modernidad y tradición que, particularmente, imprimió la sociedad española de aquellos años. En este sentido, en las películas sobre monjas y novicias que analizamos a continuación, se aprecia una clara evolución en la definición externa de los personajes, acciones y escenarios. Sin embargo, en lo que se refiere a la caracterización psicológica de las protagonistas, observamos un rotundo estancamiento.

La hermana Tomasa Carrasco, en Sor Citroën (Pedro Lazaga, 1967), es una religiosa llena de cariño y generosidad que, definida a través de un estereotipado rol de madre, se desvive por las niñas del orfanato y, en general, por todos los que la rodean. En su afán por innovar y ayudar a los demás, decide sacarse el carné de conducir, lo cual consigue tras numerosos intentos fallidos. Su nefasta destreza al volante del $2 \mathrm{CV}$, uno de los modelos emblemáticos de la época, hace que continuamente ponga en riesgo la seguridad vial y, por ello, es rebautizada con el sobrenombre de Sor Citroën. El tópico machista de que "una mujer al volante es un peligro constante" se hiperboliza aquí de forma grotesca: "monja al volante, peligro escalofriante." La consideración de mala conductora tradicionalmente otorgada a la mujer 
cuando realiza "tareas de hombres", se vuelve más peyorativa por tratarse de una religiosa. Desde luego, una monja, por su vínculo con la tradición y lo espiritual, no tiene por qué ser menos hábil para las cuestiones terrenales pero, obviamente, su contraste con el progreso (simbolizado por el Citroën 2CV) es un recurso que funciona muy bien en una comedia tan simple como la que nos ocupa'.

Al final de este periodo, encontramos otra versión de La hermana San Sulpicio, titulada La novicia rebelde (Luis Lucia, 1971)², en la que, por cierto, la protagonista es aún más torpe si cabe en materia de conducción y mecánica. En esta película, no es casual que el papel de la nueva Gloria Alvargonzález se le asignase a la joven y guapa Rocío Dúrcal, dotada de una imagen más acorde con el nuevo espíritu modernizador que la de las folclóricas de antaño, cuyas películas se encontraban ya en decadencia.

Gloria es una rica ganadera sevillana que lleva una vida alegre y desahogada. Sin embargo, no se siente realizada porque no ha conocido "a ningún hombre que valga la pena", motivo por el cual decide ingresar en un convento como antaño. Gloria posee la Diplomatura de Enfermería, por lo cual la trasladan a un hospital de Granada, donde terminará enamorándose del doctor Sanjurjo que, en esta ocasión es mejicano y está interpretado por Guillermo Murray.

Una de las imágenes que más ha perdurado es la de enfermera-monja que representa una profesión de carácter eminentemente vocacional y religioso, desempeñada por monjas que dedican su vida al cuidado desinteresado de los enfermos [...] De forma simultánea convive la imagen de la enfermera-madre, que considera la profesión de cuidar como una actividad estrechamente ligada al género femenino. Se adjudican a la enfermera los roles asignados tradicionalmente a la mujer: el de madre y esposa (Almansa, 2004:2).

Esta novicia tiene mucho de soñadora y poco de rebelde ${ }^{3}$, como denotan sus fantasías e ilusiones, que se muestran a través de vistosos y modernos números musicales. Esta concepción queda patente en el diseño de los escenarios, en las coreografías e incluso en el imaginativo vestuario firmado por Pertegaz, que también confeccionó la indumentaria religiosa. Pero, por muy atrevida que resulte la puesta en escena y por muy creativos que sean los hábitos en fucsia y amarillo, los sueños de Gloria son completamente convencionales. Por el amor de Sanjurjo, es capaz hasta de asumir con naturalidad la neutralización de su temperamento: "Si usted supiese lo bien que se pasa cuando a una la domestican...".

Con todo, es poco verosímil que una mujer de su época, con su estatus social y su formación, no encuentre otras salidas en la vida que casarse o convertirse en monja, como en

1 Recordemos que, entre las películas españolas más taquilleras de estos años, ocuparon una posición privilegiada las comedias urbanas protagonizadas por Paco Martínez Soria. Por ejemplo, en La ciudad no es para mí (Pedro Lazaga, 1966), se sigue una fórmula similar a la del caso de Sor Citröen: un anciano procedente del entorno rural sucumbe ante las maravillas de la modernidad.

2 La realización de esta nueva película se explica, en parte, si sopesamos el potencial de las adaptaciones para proporcionar productos rentables: "Las propias películas del pasado son preferibles a nuevos guiones, y otras fuentes menos frecuentes como la dramaturgia y el musical se convierten en buenas posibilidades para proyectar nuevos filmes" (Caminos y Saad, 2009).

3 En esta coproducción entre España y Méjico, aparece también el título La novicia soñadora que, sin duda, es mucho más coherente con la caracterización del personaje. Cabe apuntar que la película The sound of music (Robert Wise, 1965), distribuida en España como Sonrisas y lágrimas, recibió en América Latina el título La novicia rebelde.

Quaderns, 5 (2010), pp. 93-100 
el caso de Sor Ye-yé (Ramón Fernández, 1967). De cualquier modo, tengamos en cuenta que La novicia rebelde es una comedia musical concebida para el lucimiento de su estrella, que responde a las leyes clásicas de este género y dista bastante del texto original escrito por Armando Palacio Valdés (Piñera, 2005:277-278).

Asimismo, es necesario subrayar finalmente que, en estos títulos, se incide en el espíritu aperturista de la Iglesia en los nuevos tiempos, especialmente a través de los diálogos de los secundarios que encarnan a los religiosos y religiosas más conservadores, como la Hermana Estefanía (Isabel Garcés) en La novicia rebelde. No obstante, también se ponen en boca de las monjas palabras de conformidad con actitudes inadmisibles que, sin embargo, eran toleradas e incluso justificadas en aquella época. Por ejemplo, cuando Rosalía relata dramáticamente los episodios de violencia doméstica que sufre en su matrimonio, la bondadosa Sor Citroën le responde con expresiones como "¡si es que tú eres muy débil!," "¡te gusta que te peguen!," "¿no será que le provocas?" Y termina exigiéndole al marido: "Trátela como es debido. Las mujeres son débiles y necesitan la confianza y el cariño de su marido".

\section{PECADORAS EN CUERPO Y ALMA}

En los años setenta, las pantallas españolas fueron inundándose de temas prohibidos en el periodo anterior, como el sexo o la política. Éste fue un resultado de los cambios de todo orden que experimentaba la sociedad y de otros factores, como los constantes retrocesos de la censura a partir de 1972. Eran los comienzos del famoso destape, término que, en estos años, apareció estrechamente vinculado con las películas de alto contenido erótico, en las que el cuerpo desnudo de la mujer sirvió como un poderoso reclamo para el público que acudía a las salas de cine.

Las comedias españolas de la época fueron añadiendo matices sexuales a medida que la tolerancia censora se volvía más holgada. Triunfaron fórmulas cinematográficas como el landismo o la comedia sexy, caracterizadas por la inclusión forzada de numerosas escenas de destapes femeninos.

Los conflictos entre los papeles tradicionales y contemporáneos en la mujer son siempre resueltos a favor del establishment patriarcal [...] en su delirio machista, los protagonistas masculinos se sentirán fascinados por los modernos íncubos, pero acabarán refrendando el orden falocrático que representan al lado de las mujeres decentes (la dualidad carpetovetónica puta/ virgen de nuevo en escena) (Hernández y Pérez, 2004: 47).

Sumándose a los desnudos, se pusieron de moda en el cine de la época recursos temáticos como el incesto, el adulterio, las viudas libidinosas o las relaciones carnales entre jovencitas y señores de mediana edad. A priori, podría interpretarse esta tendencia como una marcada vocación por ir a contracorriente de los rígidos códigos morales que habían sido promovidos por el régimen dictatorial a lo largo de casi cuatro décadas. Sin embargo, el análisis de los mecanismos narrativos de las películas comerciales más taquilleras nos remite inequívocamente a una fuerte pervivencia de los valores tradicionales y de los preceptos de la religión católica, que seguían vigentes en la sociedad española.

No debe extrañarnos pues que, en este contexto, Cartas de amor de una monja (Jorge Grau, 1978) se estrenase envuelta en una gran polémica. La obra está basada en la relación 
amorosa que Sor Mariana Alcoforado (Analía Gadé) mantuvo con su confesor (Alfredo Alcón). Rompiendo el molde de la figura femenina religiosa ejemplar que había exaltado el cine español, Sor Mariana no sólo tiene fuertes conflictos espirituales sino que se convierte en una pecadora carnal que, por su condición, comete el más grave de los adulterios. El personaje de la monja aparece así humanizado, precisamente a través de sus debilidades. No obstante, esta película tampoco se libra de incorporar escenas subidas de tono y otros tópicos recurrentes de aquel entonces.

Incluso el inclasificable Jesús Franco se sintió atraído por esta historia y rodó, fiel a su estilo, una excéntrica versión "S" titulada Cartas de amor a una monja portuguesa (1977)4. En un trabajo mucho más reciente, Los años desnudos (clasificada S) (2008), Félix Sabroso y Dunia Ayaso han agregado un guiño metacinematográfico a esta clase de películas en las que se mezclaba erotismo y religión.

En otra línea, María, la Santa (Roberto Fandiño, 1977) profundiza en el entramado de intereses que rodean los milagros, las romerías y otras expresiones religiosas de culto popular a través de la historia de una niña que se ha salvado extrañamente de una muerte casi segura.

Durante aquellos años, en el seno de los ámbitos culturales alternativos, se gestaron movimientos innovadores que, más tarde, marcarían considerablemente la década de los ochenta. Pedro Almodóvar, uno de los referentes artísticos de aquellos momentos, fundó una de las comunidades religiosas más singulares que ha dado el cine español: las Redentoras Humilladas. Entre tinieblas (1983) es un original melodrama en el que "las connotaciones cinematográficas de Dominique, Historia de una monja o Sor Citroën, aunque evidentes, sufren una trasgresión temática, que las sitúa dentro de un contexto contemporáneo no carente de ironía" (Holguín, 2006: 235). No es una historia sobre cuestiones religiosas o morales, sino que trata de mujeres de carne y hueso que aman apasionadamente, sufren y luchan por conquistar sus deseos, sin verse por ello sometidas a ninguna clase de enjuiciamiento.

En esta película, Almodóvar integra elementos del pasado y del presente, dando lugar a nuevos significados. Por ejemplo, las tallas clásicas de vírgenes vestidas con las creaciones de Francis Montesinos que confecciona Sor Víbora (Lina Canalejas) sirven para expresar cínicamente la falta de modernización de la Iglesia católica. Corren malos tiempos para captar vocaciones religiosas y las pecadoras tienen ahora alternativas mucho más atractivas para redimirse que tomar los hábitos. Por eso, cuando Yolanda (Cristina Sánchez Pascual) decide refugiarse en el convento para huir de la policía, la Superiora (Julieta Serrano) expresa así su esperanza de que cunda el ejemplo: "¡Dentro de poco este pabellón estará lleno de asesinas, drogadictas y prostitutas, como en otra época!". Por otra parte, las ganas que tienen las monjas de acoger en su convento "mujeres descarriadas" también pueden interpretarse como un deseo de identificarse con ellas (Gubern, 2005: 54).

Estas religiosas consumen alucinógenos para evadirse de la realidad y adentrarse en una nueva dimensión espiritual. Sin embargo, sólo Yolanda supera finalmente la adicción porque es capaz de enfrentarse a sus problemas, mientras que la Superiora es incapaz de aceptar que su amor lésbico no haya sido correspondido.

4 Coproducción germano-suiza.

Quaderns, 5 (2010), pp. 93-100 


\section{LUCHADORAS, GUERRERAS Y ASESINAS}

A grandes rasgos, se observa que la figura femenina religiosa en el cine español ha evolucionado, sobre todo, a través de su definición externa. Con todo, los años de la Transición constituyen un punto de inflexión que determina el paso de la mitificación a la humanización de las vírgenes, santas, monjas y novicias en la gran pantalla.

La mujer en el cine de la Transición es una mujer en constitución, se está haciendo, y este proceso ha sido lento, pues entendemos que no ha sido hasta la década de los noventa (en general y salvo honrosas excepciones), pasadas las comedias madrileñas, cuando se ha producido la gestación, falta ahora el crecimiento (Guarinos, 2008: 61).

En Libertarias (Vicente Aranda, 1996), ambientada en los comienzos de la Guerra Civil, María (Ariadna Gil) es una monja huida del convento que se integra en el grupo de las milicianas de la Organización Mujeres Libres y termina contribuyendo activamente a la causa revolucionaria. Esta película resulta significativa porque representa el desarrollo personal de una mujer, que lucha por su supervivencia, sus ideales y sus sentimientos, independientemente de que sea o no una religiosa.

Teresa, el cuerpo de Cristo (Ray Loriga, 2006), como reza el propio título, no es una película concebida para idealizar e instrumentalizar las virtudes espirituales de la Santa (como Teresa de Jesús), sino un intento de presentar a Teresa de Cepeda y Ahumada (Paz Vega), una mujer rebelde y luchadora que hizo historia en tiempos difíciles para el desarrollo humano e intelectual de la sociedad, y de las mujeres en particular. En este sentido, la carga sensual extrema de las escenas en las que se recrean las visiones místicas de Teresa, suscitaron fuertes polémicas en el momento de su estreno.

Gran parte de las películas aquí mencionadas están basadas en biografías o adaptaciones literarias, lo cual conlleva casi siempre que la ambientación se realice en un marco temporal alejado del actual, en el que las connotaciones políticas, sociales y culturales del periodo que se trata desempeñan también un papel fundamental en el relato. En el extremo opuesto, La monja (Luis de la Madrid, 2005) es un thriller sobre una malvada religiosa (Cristina Piaget), desaparecida en extrañas circunstancias, que regresa del más allá para vengarse de las internas que la asesinaron cuando eran adolescentes. En cualquier caso, las propias características del género y la inclusión de personajes y escenarios de diversas nacionalidades, probablemente debida a exigencias de la coproducción entre España e Inglaterra, son los factores que justifican que este título quede prácticamente desprovisto de las connotaciones históricas presentes en las demás películas.

En España, por tanto, sigue pendiente la realización de trabajos cinematográficos que nos permitan aproximarnos a las religiosas de hoy día desde una perspectiva realista y matizada.

\section{BIBLIOGRAFÍA CITADA:}

ALMANSA MARTÍNEZ, P., "Enfermería y cine posfranquista. Una visión frívola», Enfermería Global, n 4 (2004).

CAMINOS, A. y SAAD, F., «La adaptación actual en cine: los nuevos guiones, los remakes y otras fuentes ", Memorias de las Jornadas Nacionales de Investigadores en Comunicación, n 13 (2009). 
GALÁN FAJARDO, E., «Fundamentos básicos en la construcción del personaje para medios audiovisuales», Enlaces: Revista del CES Felipe II, $\mathrm{n}^{\circ} 7$ (2007).

GUARINOS, V., «Mujer en Constitución: la mujer española en el cine de la Transición», Quaderns de cine, $\mathrm{n}^{\circ} 2$ (2008), pp. 51-62.

GUBERN, R., «Las matrices culturales de la obra de Almodóvar», en ZURIÁN, F. A. y VÁZQUEZ VARELA, C. (COORDS.), Almodóvar, el cine como pasión, Cuenca, Universidad de CastiIla-La Mancha, 2005, pp. 45-56.

HERNÁNDEZ RUIZ, J. y PÉREZ RUBIO, P., Voces en la niebla. El cine durante la Transición española (1973-1982), Barcelona, Paidós, 2004.

HOlguín, A., Pedro Almodóvar, Madrid, Cátedra, 2006.

PIÑERA TARQUE, I., «Palacio Valdés en la encrucijada metodológica de la adaptación cinematográfica», en DE LORENZO ÁLVAREZ, E. y RUIZ DE LA PEÑA, A., Palacio Valdés, un clásico olvidado (1853-2003), Asturias, KRK, 2005, pp. 245-282.

RIVERA BETANCUR, J., «Personajes con sello colombiano», en CORREA HERRERA, E. (Ed.), Narrativas audiovisuales. Personajes, acciones y escenarios, Medellín (Colombia), Universidad de Medellín, 2008, pp. 19-47.

RUIZ MUÑOZ, M. J. y SÁNCHEZ ALARCÓN, I., La imagen de la mujer andaluza en el cine español, Sevilla, Fundación Centro de Estudios Andaluces, 2008.

SÁNCHEZ ALARCÓN, I., DÍAZ ESTÉVEZ, M., MARTíN MARTíN, F. M. y RUIZ MUÑOZ, M. J., «Las películas musicales y el primer desarrollo de la estructura cinematográfica española», en MARZAL FELICl, J. y GOMEZ TARÍN, F. J. (Eds.), El productor y la producción en la industria cinematográfica, Madrid, Editorial Complutense, 2009, pp. 327-338. [CD-Rom] 